\title{
Profile Of Tourette Syndrome In Children And Adolescents From A Tertiary Care Child Psychiatry Centre In India
}

\author{
Karki U ${ }^{1}$, Sravanti L ${ }^{1}$, Sharma E ${ }^{2}$, Jacob P³ ${ }^{3}$ Kommu JVS ${ }^{4}$, Seshadri SP ${ }^{4}$ \\ 1. Senior Resident, Department of Child and Adolescent Psychiatry, NIMHANS, Bengaluru, India 2. \\ Assistant Professor, Department of Child and Adolescent Psychiatry, NIMHANS, Bengaluru, India 3. \\ Associate Professor, Department of Child and Adolescent Psychiatry, NIMHANS, Bengaluru, India 4. \\ Professor, Department of Child and Adolescent Psychiatry, NIMHANS, Bengaluru, India.
}

E-mail *Corresponding author: karkiutkarsh@gmail.com

\begin{abstract}
Introduction: Tourette Syndrome is a type of tic disorder that is not as rare as it was once thought to be. There is a paucity of literature on Tourette syndrome in children and adolescents in the Indian setting. The objectives of this study were to elucidate sociodemographic and clinical profile of children and adolescents with Tourette syndrome.

Material And Method: The present study is a retrospective chart review of children and adolescents up to age 18 years diagnosed with Tourette Syndrome in a tertiary care centre, India. This sample is from a subset of a larger sample of case records of patients with a diagnosis of tic disorder, coded as F 95, according to ICD 10 from 1st January 2014 to 31st December 2017 (4 years duration).
\end{abstract}

Results: The sample included 28 children. All of them were male, and the mean age of onset was 8.2 years. The period prevalence of Tourette syndrome was $0.22 \%$. The entire sample received pharmacotherapy and the most common medication prescribed was Risperidone followed by Clonidine, Aripiprazole, Haloperidol, and Tetrabenazine. Majority (64.28\%) of the sample had a comorbid condition. The most common comorbid conditions were Hyperkinetic Disorders followed by Obsessive Compulsive Disorder Specific and Specific Developmental Disorder of Scholastic skills

Conclusion: Tourette syndrome can be a disabling condition in school-going children. There is a need for population-based studies for estimating its prevalence in Indian subcontinent., and there is also a great need to increase awareness and sensitize the public to seek help to improve the quality of life of children and adolescents with Tourette syndrome.

Keywords: Adolescent Child, India, Tic, Tourette

\section{INTRODUCTION}

According to DSM 5 classification, Tourette syndrome (TS) is a neurodevelopmental disorder characterized by multiple motor and one or more vocal/phonic tics, lasting at least one year, with onset during childhood or adolescence. ${ }^{1}$ The first patient with Tourette's syndrome was described in the medical literature by Itard in $1825 .^{2}$ Georges Edouard Albert Brutus de la Tourette, published a cohort of nine cases in $1885 .{ }^{3}$ For many the experience of tics may only be transient, but for those with TS it is chronic and may be a debilitating mental health problem.

Although initially considered to be rare, TS is more common than previously expected, with a suggested overall prevalence of $1 / 200$ in children. TS is reported worldwide and is more common in boys than in girls with a ratio of 1.6:1 to $9: 1.4,5$ Most patients will have a complete or nearly complete remission of the disorder after 21 years of age. In $10-20 \%$ of cases, TS symptoms fluctuate, persist, or even worsen. $6,7,8$ The available evidence suggests that neurodevelopmental comorbidities in TS are the rule, rather than the exception with attention deficit/hyperactivity disorder (ADHD) being the most frequent. ${ }^{9}$ In addition, the disorder is often accompanied by obsessive-compulsive disorder (OCD), self-injurious behavior, depression, or specific learning disabilities. The use of medications is reserved for moderate to 
severe tics causing severe impairment in quality of life or when medication responsive psychiatric comorbidities are present that target both tic symptoms and comorbid conditions. ${ }^{10}$ A case series reported in 1992 from India suggested cross-cultural similarity in symptomatology, perhaps emphasizing the biological factors in the aetiology of Tourette syndrome. ${ }^{11}$ However, there is limited literature on Tourette syndrome in children and adolescents in the Indian setting. Therefore, we studied the sociodemographic and clinical profile of children and adolescents with Tourette syndrome who presented to the Child and Adolescent Psychiatry (CAP) services of National Institute of Mental Health and Neuro Sciences (NIMHANS), Bengaluru.

\section{MATERIAL AND METHOD}

The study design is a retrospective chart review of the cases that presented from $1^{\text {st }}$ January 2014 to $31^{\text {st }}$ December 2017 (four years). This sample is from a subset of a larger sample of case records of patients with a diagnosis of tic disorder, coded as F95-F95.9 according to ICD 10. Study site was the Department of child and adolescent psychiatry (DCAP), NIMHANS, Bengaluru, India which provides services to children and adolescents up to age 18. The DCAP at NIMHANS caters to children and adolescents up to age 18 . There is no definite catchment area for the CAP services although a majority is from the state of Karnataka and the neighboring states. All patients undergo a detailed clinical evaluation according to a prespecified topical format based on an unstructured psychiatric interview with both the child and the parent(s). The topical format includes sociodemographic information, presenting complaints, a history of present illness in chronological order of complaints, developmental history, temperament, family history, treatment details, and a mental status examination that involves a direct interview with the child or the adolescent. Diagnosis and management are confirmed by a consultant child and adolescent psychiatrist.

Ethics committee approval was obtained from Institutional Ethics Committee with reference number EC(BEH.SC.DIV) 13 ${ }^{\text {th }}$ Meeting/2018 of the Institute. The department offers out-patient and in-patient services to children and adolescents up to age 18. All patients are evaluated in detail by junior residents using a semi-structured psychiatric interview. Typically the informants are child's parent(s). Diagnosis and management are confirmed either by a consultant or a senior resident.

A total of 85 case records with a diagnosis of Tic Disorder as per ICD 10 were reviewed. Out of the 85 case records with Tic Disorder there were 28 children/adolescents with Tourette syndrome. Data was analyzed using descriptive statistics.

\section{RESULT}

A total of 12,662 patients attended the outpatient services during the 4-year period. Eighty-five children were identified as having a diagnosis of Tic disorder, out of which 28 $(32.94 \%)$ of them had a diagnosis of Tourette syndrome. The 4-year prevalence of TS in child and adolescent psychiatry population at this centre was $0.22 \%$.

Table 1: Socio-Demographic Profile Of Patients (N=28)

\begin{tabular}{|l|l|l|}
\hline \multicolumn{2}{|l|}{ Characteristics } & Frequency (\%) \\
\hline \multirow{2}{*}{$\begin{array}{l}\text { Age at presentation } \\
\text { (in years) }\end{array}$} & Less than 12 & $12(42.8)$ \\
\cline { 2 - 3 } & More than 12 & $16(57.1)$ \\
\hline Gender & Male & $28(100)$ \\
\cline { 2 - 3 } & Female & - \\
\hline Education & $\begin{array}{l}\text { Primary } \\
\text { school }\end{array}$ & $10(35.7)$ \\
\cline { 2 - 3 } & Middle school & $10(35.7)$ \\
\cline { 2 - 3 } & High school & $8(28.5)$ \\
\hline Family type & Nuclear & $19(67.8)$ \\
\cline { 2 - 3 } & Joint & $9(32.1)$ \\
\hline \multirow{2}{*}{ Locality } & Urban & $21(75)$ \\
\cline { 2 - 3 } & Rural & $7(25)$ \\
\hline
\end{tabular}

The mean age of presentation was 11.75 (SD$2.84)$. More than half of the sample $(57.1 \%, n=16)$ presented to our service after 12 years of age. All patients were male and were going to school. Majority $(67.8 \%, \mathrm{n}=19)$ were from a nuclear family set up and three-fourths $(n=21)$ were from an urban locality. Family history of tics was present in one patient. Table 1 shows sociodemographic profile of patients. 
Table 2: Phenomenology Of Tics

\begin{tabular}{|c|c|c|c|}
\hline Motor tics & Frequency & Vocal tics & Frequency \\
\hline $\begin{array}{l}\text { Shoulder } \\
\text { shrugging }\end{array}$ & 14 & $\begin{array}{l}\text { Throat } \\
\text { clearing }\end{array}$ & 14 \\
\hline Eye blinking & 12 & Coughing & 7 \\
\hline Head jerk & 9 & $\begin{array}{l}\text { Repeating } \\
\text { words }\end{array}$ & 4 \\
\hline Facial grimacing & 8 & Sniffing & 4 \\
\hline $\begin{array}{l}\text { Flexing and } \\
\text { extending } \\
\text { arm }\end{array}$ & 7 & & \\
\hline $\begin{array}{l}\text { Chin touching } \\
\text { shoulder }\end{array}$ & 3 & & \\
\hline Feet tapping & 2 & & \\
\hline $\begin{array}{l}\text { Jerky movement } \\
\text { of arms }\end{array}$ & 1 & & \\
\hline Lip smacking & 1 & & \\
\hline Extension of arm & 1 & & \\
\hline Nose twitching & 1 & & \\
\hline Neck jerking & 1 & & \\
\hline Head nodding & 1 & & \\
\hline
\end{tabular}

Table 2 illustrates phenomenology of motor and vocal tics in the sample. The most common type of motor tic was shoulder shrugging $(n=14)$ followed by eye blinking $(n=12)$, head jerk $(n=9)$, facial grimacing $(n=8)$ and flexing and extending the arm $(n=7)$. The most common type of vocal tic was throat clearing $(n=14)$, coughing $(n=7)$ and repeating words and sniffing $(\mathrm{n}=4)$.

\section{Table 3: Clinical Profile Of Patients (N=28)}

\begin{tabular}{|c|c|c|c|}
\hline \multicolumn{2}{|l|}{ Characteristics } & Frequency & Mean \\
\hline \multirow[t]{3}{*}{$\begin{array}{l}\text { Age of onset } \\
\text { (years) }\end{array}$} & $\begin{array}{l}\text { Preschool } \\
\text { (less than } 5 \text { years) }\end{array}$ & $1(3.5)$ & \multirow[t]{3}{*}{$8.2 \pm 2.1$} \\
\hline & $\begin{array}{l}\text { School going } \\
\text { (6-12 years) }\end{array}$ & $25(89.2)$ & \\
\hline & $\begin{array}{l}\text { Adolescence } \\
\text { (12-18 years) }\end{array}$ & $2(7.14)$ & \\
\hline \multirow{2}{*}{$\begin{array}{l}\text { Duration of } \\
\text { tics } \\
\text { (in months) }\end{array}$} & $\begin{array}{l}\text { 12-60 months } \\
\text { (1-5 years) }\end{array}$ & $21(75)$ & \multirow{2}{*}{$\begin{array}{l}41.14 \pm 25 \\
.0\end{array}$} \\
\hline & $>60$ months (5yrs) & $7(25)$ & \\
\hline \multirow{5}{*}{ Medications } & Risperidone & $16(57.1)$ & \\
\hline & Clonidine & $6(21.4)$ & \\
\hline & Aripiprazole & $2(7.14)$ & \\
\hline & Haloperidol & $2(7.14)$ & \\
\hline & Tetrabenazine & $2(7.14)$ & \\
\hline $\begin{array}{l}\text { Duration of } \\
\text { follow up (in } \\
\text { months) }\end{array}$ & & & $9.9 \pm 8.22$ \\
\hline
\end{tabular}

Majority of patients $(89.2 \%$; $n=25)$ had onset of tics between 6 to 12 years of age i.e. middle childhood, with the mean age of onset being 8.2 (SD-2.1). Three-fourths of the sample $(n=21)$ had duration of tics between 1 to 5 years. The most common medication prescribed was Risperidone (57.1\%; $\mathrm{n}=16)$ followed by Clonidine $(21.4 \% ; \quad n=6), \quad$ Aripiprazole, Haloperidol and Tetrabenazine. The mean duration of follow up of the sample was 9.9(SD8.22) months. Clinical profile of patients is summarized in Table 3.

Table 4: Pattern of comorbidities in patients with Tourette Syndrome $(\mathrm{n}=28)$

\begin{tabular}{|l|l|}
\hline Comorbidities & Frequency (\%) \\
\hline Hyperkinetic disorders & $8(28.57)$ \\
\hline OCD & $4(14.28)$ \\
\hline SDDSS & $3(10.7)$ \\
\hline Hyperkinetic disorders + OCD & $2(7.14)$ \\
\hline $\begin{array}{l}\text { Hyperkinetic disorders + Social } \\
\text { Phobia }\end{array}$ & $1(3.57)$ \\
\hline Conduct disorder & $1(3.57)$ \\
\hline Pervasive developmental disorders & $1(3.57)$ \\
\hline Dysthymia & $1(3.57)$ \\
\hline
\end{tabular}

* OCD -Obsessive compulsive disorder, SDDSS Specific Developmental Disorder of Scholastic Skills

Table 4 illustrates the comorbidities. Majority $(64.28 \%, \mathrm{n}=18)$ of the sample had a comorbid condition. Most common comorbid conditions were Hyperkinetic disorders $(28.75 \% ; n=8)$, followed by OCD $(14.28 \% ; n=4)$ and SDDSS $(10.7 \% ; \mathrm{n}=3)$.

\section{DISCUSSION:}

Crude prevalence of $0.22 \%$ is lower than $0.4-1 \%$ reported in the west. ${ }^{12,13}$ While the estimates in west are from epidemiological studies, ours is a clinic-based population. This explains the lower prevalence in our sample. The National Mental Health Survey (2015-2016) ${ }^{14}$ did not mention prevalence of tic disorders, so prevalence in general population in the Indian context is unknown. TS has a typical course of progression and is known to peak in severity between 10-12 years ${ }^{12}$ and the mean age of presentation of our cases was 11.75 years. Age at help-seeking corresponds to the age of worsening of the condition. ${ }^{12}$ While literature suggests a male to 
female ratio of 1.6:1 to $9: 1,4,5$ all the cases in our sample were males. Perhaps, this can be explained by referral bias. The majority of the patients were from nuclear families and an urban setting. The hospital is situated in one of the major urban cities of India and its location can explain the predominant sociodemographic characteristics of the sample.

Majority of the sample (89.2\%) had an onset between 6-12 years of age i.e. middle childhood, as compared to the typical onset between 4-6 years described in literature. ${ }^{12}$ This difference in age of onset could partly be due to recall bias with a possible tendency to underreport subtle tics in the initial stages. However, there here is a need to explore if this is true to population in the Indian sub-continent.

Tics can manifest as any movement or sound that human body can make, which can range from simple/inarticulate movements/sounds to very complicated forms. ${ }^{15}$ The phenomenology of our sample is similar to that reported across the globe, typically characterised by eyeblinking, shoulder shrugging, head jerks, facial grimacing, throat clearing, coughing, sniffing and repeating words. The more complex presentations such as flexing extending arm and feet tapping were also noted as biological underpinnings. Around three fourth of the sample had duration of 1-5 years of illness at the time of presentation which suggests delay in seeking services but detail information about visit to other centres or services could not be obtained and cannot be ruled out.

Risperidone followed by clonidine were the commonly prescribed medications, which is in line with the European Child and Adolescent Psychiatry guidelines 2011,16 that haloperidol, pimozide, risperidone, alpha- 2 agonists such as clonidine and guanfacine have level of evidence A for use in tic disorders. Haloperidol and pimozide are the only two FDA approved treatments for tics, although they are not currently recommended as the first-line pharmacotherapy because of their adverse sideeffect profile. ${ }^{17}$ Treatment should begin with psychoeducation followed by pharmacotherapy or non-pharmacotherapeutic interventions such as habit reversal training (HRT). ${ }^{10}$ Apart from medications, in our sample psychoeducation with HRT was provided to all.
The average duration of follow up of approximately 10 months in this population is not long enough, given its worsening course described in this age-group. ${ }^{13}$ This suggests that often children and families are lost to follow-up. Therefore, there is a need to sensitize the public/improve awareness about this condition in the population, so it can help in identification of children enduring this illness and offer treatment accordingly.

\section{CONCLUSION:}

Tourette syndrome can be disabling in schoolgoing children that can affect their general wellbeing and school performance. However, its prevalence in general population remains unknown. This calls for studies for example in schools to estimate its true prevalence. The later age at onset noted in our sample has important clinical and research implications. This finding needs to be replicated in diverse and larger population studies. The short duration of follow-up is alarming for a clinician, there is a need to improve awareness about this condition in general population.

\section{ACKNOWLEDGEMENT: None}

\section{FUNDING: None}

\section{CONFLICT OF INTEREST: None}

\section{REFERENCES:}

1. American Psychiatric Association. DSM-5. St. Louis: American Psychiatric Association; 2013.

2. Itard JMG. Memoire sur quelques fonctions involontaires des appareils de la locomotion de la prehension et de la voix. Archiv Gen Med 1825; 8:385407.

3. Gilles de la Tourette: G Etude sur une affection nerveuse caracterisee par de l'incoordination motrice accompagnee d'echolalie et de coprolalie. . Arch Neurol (Paris) 1885; 9(19-42):158-200.

4. Robertson MM. A personal 35 year perspective on Gilles de la Tourette syndrome: prevalence, phenomenology, comorbidities, and coexistent psychopathologies. Lancet Psychiatry. 2015;2:68-87. https://doi. org/10.1016/S2215-0366(14)00132-1.

5. Scharf JM, Miller LL, Gauvin CA, et al. Population prevalence of Tourette syndrome: a systematic review and meta-analysis. Mov Disord. 2015;30:221-8. https://doi.org/10.1002/mds.26089.

6. Cath DC, Hedderly T, Ludolph AG, Stern JS, Murphy T, Hartmann A, et al. European clinical guidelines for Tourette syndrome and other tic disorders. Part I: 
assessment. Eur Child Adolesc Psychiatry.2011;20(4):155-71. doi:10.1007/s00787011-0164-6

7. Hirschtritt ME, Lee PC, Pauls DL, Dion Y, Grados $M A$, Illmann $C$, et al. Lifetime prevalence, age of risk, and genetic relationships of comorbid psychiatric disorders Tourettesyndrome.JAMAPsychiatry.2015;72(4):32533. doi:10.1001/jamapsychiatry.2014.2650

8. Robertson MM, Eapen $V$, Singer HS, Martino D, Scharf JM, Paschou P, et al. Gilles de la Tourette syndrome. Nat Rev Dis Primers .2017; 3:16097. doi:10.1038/nrdp.2016.97

9. Cravedi E, Deniau E, Giannitelli M, Xavier J, Hartmann A, Cohen D, et al. Tourette syndrome and other neurodevelopmental disorders: a comprehensive review. Child and Adolescent Psychiatry and Mental Health.2017;11:59,2-12. https"//doi.org/10.1186/s13034-017-0196-x

10. Murphy TK, Lewin AB, Storch EA, Stock $S$ and American Academy of Child and Adolescent Psychiatry (AACAP). Practice Parameter for the Assessment and Treatment of Children and Adolescents with Tic Disorders. Journal of American Academy of Child and Adolescent Psychiatry. 2013;52:12

11. Psychological Reports, 1992, 70, 667-668. Psychological Reports 1992 Gilles De La Tourette Syndrome in India: Two cases ' V. Eapen and Shoba Srinath. National Institute of Mental Health and Neuro Sciences.

12. Bloch MH, Leckman JF. Clinical course of Tourette syndrome. Journal of Psychosomatic Research. 2009; 67:497-501.

13. Robertson MM. The prevalence of epidemiology of Gilles de la Tourette syndrome. Part 1: The epidemiological and prevalence studies. Journal of Psychosomatic Research. 2008; 65: 461-472.

14. National Mental Health Survey of India, 2015-2016. Supported by Ministry of Health and Family Welfare Government of India.

15. Kurlan R. Tourette's Syndrome. $N$ Eng J Med. 2010;363:2332-8

16. Roessner V, Plessen KJ, Rothenberger A, Ludolph AG, Rizzo R SL. European clinical guidelines for Tourette syndrome and other tic disorders. Part II: pharmacological treatment. Eur Child Adolesc Psychiatry. 2011;20(4):173-96.

17. Schaill L, Erenberg G, Berlin CM Jr, Budman C, Coffey BJ JJ. Contemporary assessment and pharacotherapy of Tourette syndrome. Neuro Rev. 2006;3(2):192-206. 